\title{
Trabalho temporário com uma alternativa na prestação de serviços
}

\author{
Temporary work with an alternative in the provision of services \\ Trabajo temporal con alternativa en la prestación de servicios
}

Recebido: 31/01/2022 | Revisado: 05/02/2022 | Aceito: 06/02/2022 | Publicado: 12/02/2022

\author{
José Carlos Guimaraes Junior \\ ORCID: https://orcid.org/0000-0002-8233-2628 \\ Universidade do Estado do Amazonas-Rede Bionorte, Brasil \\ E-mail: profjc65@hotmail.com, Brasil \\ Paulo Roberto Ribeiro Marinho \\ ORCID: https://orcid.org/0000-0002-3661-7251 \\ Instituto Federal de educação, Ciência e Tecnologia de São Paulo, Brasil \\ E-mail: roberto.marinho@unesp.br \\ Thiago Gomes Nascimento \\ ORCID: http://orcid.org/0000-0002-2432-3117 \\ Aix-Marseille Université, França \\ E-mail: tgn.1980@gmail.com \\ Katia Regina Araujo de Alencar \\ ORCID: https://orcid.org/0000-0002-5800-3197 \\ Universidade de Brasilia, Brasil \\ E-mail: katiadealencar@gmail.com, Brasil \\ Maycon Pereira Silva \\ ORCID: https://orcid.org/0000-0002-1276-6981 \\ Instituto Federal de educação, Ciência e Tecnologia do Espírito Santo, Brasil \\ E-mail: mayconps@gmail.com, Brasil
}

\begin{abstract}
Resumo
A gestão organizacional é uma ferramenta que deve avaliar e reconhecer a evolução da gestão das empresas em todos os setores; assim, as diversas práticas publicadas nos programas de gestão de pessoas oferecem exemplos de inovação e criatividade na realização dos processos produtivos que merecem e precisam ser disseminadas para serem utilizadas como modelos de gestão em outras organizações. Este artigo tem como objetivo a identificação e análise da importância do trabalho temporário para as organizações, oferecendo subsídios, caracterizando as vantagens e desvantagens promovendo assim uma sugestão para a implantação desse sistema de gestão de Recursos Humanos visando a melhoria da prestação dos serviços e na concretização dos objetivos organizacionais. Trata-se de um estudo exploratório e descritivo, com apoio de pesquisa bibliográfica. Também ocorreu a aplicação de questionário em duas empresas públicas. Os resultados apontaram que nas práticas de recursos humanos das organizações pesquisadas foram identificadas práticas voltadas ao planejamento, estímulo a criatividade dos funcionários e avaliação do clima organizacional. $O$ estudo conclui que a terceirização de mão de obra em serviços é uma alternativa referendada por meio da legislação pertinente, a qual entre vantagens e desvantagens possui sua prática vinculada a redução de custos e maior flexibilidade na operacionalização dos serviços prestados ao cliente.
\end{abstract}

Palavras-chave: Administração de serviços; Mão de obra temporária; Gestão de pessoas.

\begin{abstract}
Organizational management is a tool that must assess and recognize the evolution of company management in all sectors; thus, the various practices published in people management programs offer examples of innovation and creativity in carrying out production processes that deserve and need to be disseminated to be used as management models in other organizations. This article aims to identify and analyze the importance of temporary work for organizations, offering subsidies, characterizing the advantages and disadvantages, thus promoting a suggestion for the implementation of this Human Resources management system aimed at improving the provision of services and the realization of organizational objectives. This is an exploratory and descriptive study, supported by bibliographic research. A questionnaire was also applied in two public companies. The results showed that in the human resources practices of the organizations surveyed, practices aimed at planning, encouraging employees' creativity and evaluating the organizational climate were identified. The study concludes that the outsourcing of labor in services is an alternative endorsed by the relevant legislation, which, between advantages and disadvantages, has its practice linked to cost reduction and greater flexibility in the operation of the services provided to the customer.
\end{abstract}

Keywords: Service administration; Temporary employment; People management. 


\begin{abstract}
Resumen
La gestión organizacional es una herramienta que debe evaluar y reconocer la evolución de la gestión empresarial en todos los sectores; así, las diversas prácticas publicadas en los programas de gestión de personas ofrecen ejemplos de innovación y creatividad en la realización de procesos productivos que merecen y necesitan ser difundidos para ser utilizados como modelos de gestión en otras organizaciones. Este artículo tiene como objetivo identificar y analizar la importancia del trabajo temporal para las organizaciones, ofreciendo subsidios, caracterizando las ventajas y desventajas, promoviendo así una sugerencia para la implementación de este sistema de gestión de Recursos Humanos dirigido a mejorar la prestación de servicios y la realización de los objetivos organizacionales. Se trata de un estudio exploratorio y descriptivo, apoyado en investigación bibliográfica. También se aplicó un cuestionario en dos empresas públicas. Los resultados mostraron que en las prácticas de recursos humanos de las organizaciones encuestadas, se identificaron prácticas dirigidas a la planificación, el fomento de la creatividad de los empleados y la evaluación del clima organizacional. El estudio concluye que la tercerización de mano de obra en los servicios es una alternativa avalada por la legislación pertinente, que, entre ventajas y desventajas, tiene su práctica ligada a la reducción de costos y mayor flexibilidad en la operación de los servicios prestados al cliente.
\end{abstract}

Palabras clave: Administración de servicios; Empleo temporal; Gestión de personas.

\title{
1. Introdução
}

Durante décadas, mudanças sociais, econômicas e de tecnologia influenciaram todas as atividades de trabalho, onde as organizações identificaram uma demanda de ajustes e/ou mudanças, de maneira que possam a continuar a tornarem-se competitivas no mercado, e sendo assim inicia-se a modalidade de contratação temporária torna-se uma realidade no mercado Brasileiro.

O processo de globalização das atividades e do trabalho, além do processo imersão na integração econômica mundial, torna-se uma realidade e necessidade sociocultural, de maneira que essa nova dita reorganização geopolítica, onde países agrupam-se em blocos, influenciam diretamente todas as atividades econômicas.

Consoante Pagnoncelli (1993), o perfil da empresa competitiva na década de 1990 apresentava seis características relevantes como foco, flexibilidade, custos competitivos, obsessão pela qualidade, produtividade e parcerias.

Objetivando um maior crescimento, as organizações do século 21 a partir das características mencionadas e das atuais demandas de mercado investiram na contratação de mão de obra temporária.

Assim, com um processo de produção mais descentralizado inspirou a metamorfose da antiga empresa constituída por uma unidade produtiva jurídica, física e social que assegurava no seu ser todas as tarefas necessárias à continuação da atividade produtiva e cujo coletivo de trabalhadores permanentes ficava sujeito a um estatuto comum. (Redinha, 1995)

Os processos de ajustes dos blocos econômicos contribuíram para um novo modelo de gestão do trabalho, onde a tensão da concorrência e a divisão internacional entre países forçaram as antigas organizações a se transformarem em novos modelos organizacionais de gestão.

A globalização força a maximização do lucro das empresas, impulsionadas pelas mudanças na forma de relacionamento entre seus colaboradores e gestores, onde a contratação temporária flexível, torna o conceito de estabilidade, não confundir com a estabilidade no sérvio público, dessa forma, a contratação dos trabalhadores de forma temporária, torna-se uma realidade para o desenvolvimento das atividades laborais.

De acordo com a Legislação atual no Brasil, que gerencia as contratações de trabalhadores, a Consolidação das Leis do Trabalho-CLT, além de se tornar uma realidade em países desenvolvidos, mas ainda uma tendência no Brasil, inúmeras empresas nacionais oferecem a contratação de mão de obra por projeto, por tempo, ou em outras modalidades que “quebrem” o conceito de estabilidade aos seus colaboradores. Essa nova modalidade tem como objetivo, a redução de custos com mão de obra, podendo contrata profissionais mais bem qualificados e que ofereçam algum diferencial importante que permita essas empresas a tornarem-se competitivas no mercado Global.

Ainda para muitas empesas e profissionais, a modalidade de contrato temporário é considerada uma excelente alternativa de gestão, tanto no sentido de que profissionais mais qualificados podem ascender profissionalmente e mais rápido 
nas empresas, quando a gerar oportunidades para os profissionais a se qualificarem em outras áreas em que o mercado acena que são importantes.

Não há se se negar que a modalidade de contratação temporária gera maiores expectativas e maiores economias as empresas, pois os custos de um funcionário com a chamada carteira assinado, gera custo elevadíssimos as empresas, e em alguns casos, comprometem até $80 \%$ de todas as receitas da empresa, situação essa que torna inviável continuar com essa modalidade formal de contratação.

Por outro lado, surgem empresas que se tornam especializadas em buscar esses perfis de profissionais no mercado, promovendo um recrutamento e, posteriormente, oferecer esse perfil as empresas. Para a empresa que está contratando, os custos com esse processo) recrutamento e seleção), tornam-se muito mais competitivos do que a empresa ter na sua estrutura organizacional, toda uma estrutura de Gestão de Pessoas voltadas para esses processos.

Dessa forma, a formalização desse tipo de contrato ocorre entre as partes respeitando-se as normas jurídicas (CLT) em vigor.

Algumas desvantagens dessa modalidade de contratação podem ser identificadas, tais como; alguns profissionais se adequam de forma muito rápida aos padrões de trabalhos já existentes na empresa (e que não estavam promovendo resultados satisfatórios) e a falta de comprometimento organizacional, tendo em vista que ele não faz parte da organização.

Kotler (1996), comenta que "ao longo da história da administração, o paradigma mecanicista que defendia a visão racional, em que a empresa é uma máquina e as pessoas são engrenagens, foi gradativamente substituído pelo paradigma holístico onde a empresa é um grupo de pessoas ativo e estruturado".

Dentro dessa análise, evidenciamos a importância do aprimoramento de processos de treinamento e desenvolvimento pessoal contínuos, como sendo um dos mais importantes influentes mecanismos para a transformação dessas empresas e um novo alinhamento do ranking nacional e internacional.

\section{Metodologia de Pesquisa}

Por planejamento de pesquisa entende-se a previsão racional de um evento, atividade, comportamento ou objeto que se pretende realizar a partir da perspectiva científica do pesquisador. Como previsão, deve-se compreender a explicitação do caráter antecipatório das ações e, como tal, ir ao encontro de uma racionalidade informada pela perspectiva teóricometodológica da relação entre o sujeito e o objeto da pesquisa.

Além disso, deve fornecer rotinas de pesquisa que possibilitem o alcance dos objetivos definidos, de forma que os melhores resultados sejam alcançados com o menor custo (Barreto et al., 1998).

Consoante os estudos de Gil (2019), Prodanov e Freitas (2013) e Zanella (2013), com relação aos seus objetivos a pesquisa com base em seus objetivos em pesquisa exploratória, que visa proporcionar maior familiaridade com o problema, a fim de torná-lo mais explícito ou construir hipóteses. Já a pesquisa descritiva identifica as características de uma determinada população ou fenômeno (Gil, 2010; 2019).

Boaventura (2004) relata que o melhor exemplo é o levantamento de dados e informações. As explicações visam identificar os fatores que interferem ou condicionam a ocorrência de fenômenos, como pesquisas experimentais baseadas em eventos passados.

Esta pesquisa foi realizada em duas etapas interdependentes e interligadas, sendo necessária, para sua complementaridade e inter-relacionamento, uma pesquisa bibliográfica sobre o tema gestão de pessoas, além de ter envolvido o levantamento de informações de fontes secundárias e primárias. No entender de Prodanov e Freitas (2013), as pesquisas de cunho bibliográfico são feitas com base em livros, artigos, teses, dissertações e demais materiais que anteriormente já versaram sobre as temáticas estudadas. 
Ao realizar a análise das respostas obtidas na aplicação dos questionários, obteve-se como resultado informações qualitativas, que serviram de base para mitigar algumas situações identificadas que servirão de base para que gestores de empresas públicas utilizem esses dados como base de decisão -Fazendo processo.

Sobre o universo e a amostra, pode-se dizer que pesquisa foi realizada em duas empresas públicas, que por questões de segurança dos dados seus respectivos nomes não podem ser mencionados neste espaço. O instrumento de pesquisa utilizado foi um questionário, elaborado com 5 (cinco) questões fechadas para a identificação de características qualitativas, a fim de identificar a percepção que os gestores dessas empresas públicas observam, a respeito de uma avaliação da força de trabalho temporária existente nas empresas.

\section{O Processo de Prestação e Qualidade dos Serviços}

Drucker (1987) reitera que as mudanças podem ser vistas como oportunidades, as quais por sua vez precisam ser devidamente aproveitadas para resultar em algo que seja lucrativo. Isto remete ao que é visto em Rabbi e Monteiro (2018) quando afirmam que uma das funções precípuas das empresas diz respeito a análise do ambiente externo para detectar não somente as oportunidades, mas também as possíveis ameaças e crises que podem desestabilizar o sistema organizacional (Inácio, 2021).

O processo de crescimento evolutivo das atividades das empresas é uma realidade incontestável onde as empresas, as quais pensando nas suas atuações em mercados globalizados, devam ter como objetivo primaz a oferta de serviços, com produtos de altíssimas qualidades, gerando produtos e serviços que atendam com excelência as satisfações e necessidades de seus dos clientes. Nisto alguns elementos se tornam fatores condicionantes para a sobrevivência destas companhias.

Um deles é a qualidade, a qual no entender de Slack, Chambers e Johnston (2009) significa fazer aquilo que precisa ser feito de forma correta, sem deixar espaços para retrabalhos. Outro ponto a ser destacado é o que diz respeito a inovação, a qual, em síntese, significa fazer o novo, sendo que este novo agrega valor aos produtos e serviços oferecidos pela companhia, elevando assim o seu nível de competitividade (García-Aviles, Carvajal-Prieto, Lara-Gonzáes et al.,2018; Nascimento-e-Silva, 2017; Silva et al.,2020).

Queiroz (1998), afirma que “nessa análise, a competição tem reduzido as organizações, por conta das necessidades de otimização econômico-financeira. Diante da grande dificuldade enfrentada pelas empresas no que diz respeito aos encargos jurídicos, sociais e tributários dos órgãos governamentais, as empresas são obrigadas a reduzir seus gastos relacionados principalmente a mão de obra.

Com as diversas metas para se alcançar as produtividades empresariais, as empresas transferem para terceiros especializados onde, indubitavelmente as relações de trabalho caminham para um processo de informalidade, facilitando a exploração desses trabalhadores.

Apresentada essa realidade, as empresas gerenciadas pelas demandas mais atuais esmeram seus esforços na prestação de serviços e venda de produtos que espelhem a sua atividade fim, focando suas competências, onde possuem flexibilidade para adaptação e sobrevivência aos processos de mudanças organizacionais mais importantes e necessários. Dentre os eixos estruturantes necessários para o alcance da qualidade na prestação de serviços, destaca-se o grau de eficiência das pessoas que trabalham na execução destas tarefas. Sendo o elemento humano o grande responsável pela geração dos resultados nas companhias, o investimento na qualificação dos profissionais responsáveis pela prestação de serviços é um dos fatores condicionantes para o sucesso das companhias que atuam neste mercado (Carvalho, 2020).

Gumesson (1981) diz que para a prestação de um serviço profissional, os seguintes itens são levados em consideração: O serviço deve ser prestado por pessoal qualificado, ter caráter consultivo e foco na resolução de problemas; o profissional deve 
ter identidade, ser conhecido no mercado por sua especialização; o serviço deve ter uma tarefa atribuída pelo comprador ao fornecedor e o profissional deve ser independente dos fornecedores de outros serviços ou bens.

Para que uma empresa consiga desenvolver suas atividades com qualidade total nos serviços, faz-se necessário oferecer uma revolução nos processos educacionais por meio da oferta de aprendizados contínuo, e no aproveitamento de oportunidades para melhoria dentro da estrutura organizacional, assim, as organizações aprendem com os equívocos, identificando-os, e buscam evita-los quando da realização de outros processos. Este processo de detecção de pontos falhos e busca pelo aprimoramento dos processos remete ao que se vê no Sistema Toyota de Produção, onde a melhoria contínua é um dos sustentáculos deste modo de se gerenciar um sistema produtivo. O percentual de erros diminui e as oportunidade de melhorias nas atividades se eleva, agregando valor para o trabalho desenvolvido e, por conseguinte, reduzindo os eventuais desperdícios (Graban, 2013; Paraschivescu et al., 2015; Rodrigues, 2020).

Pode-se considerar que há uma relação estreita entre a qualidade do serviço prestado e a satisfação da clientela (Milan, Brentano et al., 2008). Por esta razão, quanto mais elevado for o patamar de qualidade, maior será o grau de satisfação deste cliente com o que ele percebeu a respeito do serviço a ele ofertado. Em uma análise generalista, as organizações que possuem funcionários preocupados com a satisfação de seus clientes, possuem um desempenho na prestação de seus serviços importante; e dessa forma, identifica-se que a satisfação dos clientes é relacionada diretamente relacionada às pessoas que oferecem seus serviços, seja através de suas atitudes durante a prestação do serviço, ou mesmo nos resultados obtidos.

\section{Atividade Temporária no Mundo}

Durante muito tempo, o trabalho temporário foi considerado uma atividade fora da lei, que cresceu descontroladamente e sem regulamentação específica nos países da Europa Ocidental e nos Estados Unidos. Além disso, esta modalidade de contratação de pessoas não se enquadrar nos conceitos tradicionais do Direito do Trabalho à época (Brasil, 1943).

No Brasil, o trabalho temporário passou por uma fase de crescimento como atividade não reconhecida legalmente, até ser regulamentada pelo Lei 6.019, de 3 de janeiro de 1974, e teve como inspiração o estatuto de trabalho temporário da França. Assim, o regime de trabalho temporário foi estabelecido pela referida legislação.

Por definição legal, trabalho temporário é aquele realizado por uma pessoa física para uma pessoa jurídica (empresa), com vistas ao atendimento de demandas transitórias ou excepcionais em seu quadro funcional (Brasil, 2017). Observa-se que a temática do trabalho que prevê o cumprimento de todas as garantias trabalhistas ao trabalhador, com ausência de possíveis subtrações destes direitos está se tornando algo cada vez menos frequente de se ver. Isto porque a chamada reestruturação produtiva faz com que boa parte das empresa opte por oferecer trabalhos temporários com duração determinada dos contratos, evitando-se assim eventuais imprevisibilidades no atendimento das demandas destas companhias (Silva, Bantim e Costa, 2020).

Consoante o estudo empreendido por Silva, Bantim e Costa (2020), no mundo do trabalho nacional, esta situação da terceirização vê na publicação da Reforma Trabalhista feita no governo de Michel Temer (Brasil, 2017) uma potencialização, isto porque por meio desta mudança todas as atividades de uma empresa passam a ter a sua terceirização autorizada por meio legal. Com isso, as companhias podem transferir a execução de seus serviços para terceiros, os quais podem pagar salários menores e contratar temporários sem a preocupação de firmar contratos efetivos de trabalho junto aos seus colaboradores. Diante da escassez da oferta de trabalho formal, há quem aceite a esta sistemática de contratações temporárias. Já aqueles que não possuem qualificação ou idade para se enquadrar neste contexto, opta pelo trabalho por conta própria, o qual tem na chamada uberização do trabalho um de seus exemplos mais emblemáticos (Abílio, 2020; Slee, 2017).

O trabalho temporário pode ser visto como um processo que canaliza a capacidade de trabalho disponível no mercado para viabilizar os objetivos organizacionais (Wiegerinck, 1995). Além disso, pode-se conceber que o trabalho temporário é 
uma alternativa da qual as empresas fazem uso para complementar o seu quadro funcional para atender alguma demanda extra de trabalho ou ainda para substituição de algum funcionário que porventura tenha de se afastar de suas atividades (Pinto, 2004).

Considera-se que o trabalho temporário não difere do trabalho estável na sua essência, mas na sua administração e nos procedimentos que lhe são aplicados. No caso de seleção temporária de trabalho, conhecida como inscrição, os candidatos são avaliados e classificados de acordo com suas aptidões, com o objetivo de encontrar uma oportunidade de trabalho para todos os candidatos.

De acordo com a Lei 6.019 (Brasil, 1974), a empresa de trabalho temporário é a pessoa física ou jurídica urbana, que disponibiliza temporariamente trabalhadores devidamente qualificados para outras empresas, por elas remunerados e assistidos. O funcionamento da empresa ficará a cargo do registro na Secretaria Nacional do Trabalho do Ministério do Trabalho e Previdência Social.

Influenciadas por fatores funcionais e econômicos, as empresas referem-se ao trabalho temporário por meio de agências especializadas ou o fazem diretamente com os trabalhadores temporários.

A Lei 6.019 (Brasil, 1974) também dispõe sobre o contrato entre a empresa de trabalho temporário e a empresa contratante do serviço ou cliente, que deve ser por escrito, deve conter o motivo da demanda do trabalho temporário e as modalidades de remuneração pela prestação do serviço, não pode ultrapassar três meses, exceto para os serviços que obtenham autorização do Ministério Público do Trabalho e Segurança Social.

O contrato entre a empresa de trabalho temporário e o trabalhador temporário também deve ser por escrito e deve conter os seguintes direitos: (Lei 6.019/74 art. 12): remuneração equivalente à recebida por empregados da mesma categoria de tomador ou cliente, calculada por hora, garantindo, em qualquer hipótese, a percepção do salário mínimo regional; jornada de trabalho de oito horas e horas extras remuneradas não superiores a duas, com acréscimo de $20 \%$ (vinte por cento); férias proporcionais; descanso semanal remunerado; sobretaxa noturna; indenização por dispensa sem justa causa ou rescisão normal do contrato, correspondente a 1/12 (um duodécimo) da remuneração recebida; seguro de acidentes de trabalho; proteção da segurança social nos termos da lei orgânica da segurança social.

Relativamente ao acordo entre as partes, quando a empresa de trabalho temporário está envolvida no processo, são celebrados dois contratos, um entre a empresa prestadora de serviços e a empresa de trabalho temporário e o outro entre o trabalhador temporário e a empresa de trabalho temporário. Quando não há intermediação da empresa de trabalho temporário, o contrato é celebrado entre a empresa destinatária do serviço e o trabalhador temporário. A eficácia de cada contrato depende do outro.

Para atender às necessidades dos clientes, o trabalhador temporário pode desenvolver uma competência única na execução de trabalhos temporários. Qualificar seu tempo optando ou não pela ocupação permanente de trabalho temporário e, de certa forma, você pode ganhar mais do que ganharia se fosse empregado permanente.

Portanto, a regulamentação do contrato temporário ocorre em 1974, tornando-se uma ferramenta essencial e importante para o crescimento e aproveitamento da mão de obra especializada e no desenvolvimento da prestação de serviços; além de ser uma ferramenta importante na gestão da sazonalidade da mão de obra necessária, ou na reposição temporária excepcional de seus profissionais, em decorrência de acidentes, férias, licença-maternidade, doenças e outras ausências.

Com o objetivo de poupar tempo, as empresas aderentes optam por outras empresas especializadas no serviço de recrutamento e seleção, contratação, pagamento, cobrança e rescisão de mão de obra temporária, cabendo à entidade apenas a responsabilidade pela seleção final dos candidatos previamente selecionados. 
O trabalho temporário tem a vantagem de oferecer maior agilidade na mobilização e desmobilização da força de trabalho quando há necessidade de contratação de excedentes. Pode ser solicitado rapidamente por profissionais treinados para gerar maior produtividade e reduzir a ociosidade de pessoas e instalações.

Entre os benefícios do trabalho temporário, a redução de custos neste tipo de contrato (Soeiro, 2013). Trata-se de uma vantagem competitiva dada a redução dos encargos e encargos bancários do trabalho temporário. Todavia, há um ponto crítico na contratação de profissionais temporários é a não padronização dos serviços, pois muitas vezes os profissionais permanecem apegados a modelos inusitados ou em desuso para a atividade exercida no momento.

\section{Análise dos Resultados Obtidos}

Cada item do Critério de Pessoas de cada relatório foi investigado criteriosamente, sendo destacadas as atividades que serviriam de base para uma proposta de melhoria para a área de RH de organizações públicas, bem como um exemplo de como foi realizada a pesquisa. Algumas atividades extraídas serão mencionadas abaixo do relatório de gestão das instituições pesquisadas.

- Planejamento pela Coordenação de Pesquisa e Recursos Humanos - CPRH desenvolvido no âmbito do planejamento estratégico das empresas, e não como uma atividade isolada, cobrindo as necessidades de treinamento de todos os colaboradores (Mourão et al., 2009).

- Implantação do Plano de Ação Diretor, visando implementar as melhorias e reduzir as principais lacunas encontradas pelos examinadores das empresas. As sugestões do Plano Diretor de Ação são trabalhadas, resultando em planos de ação específicos, com responsáveis claramente definidos e prazo fixo para execução, os quais são implementados, após aprovação do conselho de administração. No entender de Maximiano (2011), Nascimento-e-Silva (2017) e Silva (2019), o planejamento é uma ação gerencial decisória, a qual define o futuro que a empresa quer alcançar e que deve estar alinhada a estratégias e metas bem estabelecidas com vistas a sua consecução.

- A implantação do Programa de Ideias Criativas contempla o recebimento, seleção e gestão de ideias e sugestões, visando a participação ativa e espontânea dos colaboradores na busca pela melhoria do ambiente de trabalho e do desempenho operacional e financeiro da empresa. Bruno-Faria, Veiga e Macêdo (2008) apontam que a criatividade representa um diferencial competitivo para as organizações e deve estar agregada a sua cultura, de maneira que todos na companhia desempenhem suas atividades buscando sempre um diferencial em seus respectivos resultados.

- Execução de pesquisa que explorem o clima organizacional, buscando a reflexão do grau de satisfação dos colaboradores em relação aos processos e das práticas de gestão, interpelando os seguintes tópicos: benefícios, comunicação, espírito de equipe, higiene e segurança industrial, liderança, reconhecimento e recompensa, relação com o trabalho, remuneração e treinamento e desenvolvimento. Puente-Palacios e Freitas (2006) relatam que é preciso que as companhias se dediquem a análise de seu clima organizacional, não somente para conhecer mais sobre o comportamento de seus colaboradores, mas também para o alcance da efetividade organizacional por meio da coleta do ponto de vista dos funcionários sobre o seu local de trabalho.

Todas as sugestões apresentadas neste trabalho foram elaboradas a partir de exemplos de práticas exitosas, selecionadas entre tantos outros contidos nos relatórios de gestão das quatro instituições pesquisadas.

$\mathrm{Na}$ apresentação das sugestões, foram feitas adaptações de forma a viabilizá-las, para ser incorporada na cultura das instituições. De referir ainda que a prática do benchmarking é essencial para qualquer organização que almeje ser reconhecida pela sua excelente gestão (Portella, 2021). Quanto à questão da administração de pessoal, não foram feitas sugestões, tendo em vista que esta atividade é realizada de acordo com a lei e os sistemas integrados de governo. 


\section{Conclusão}

Dentre as diversas formas de flexibilização do trabalho na prestação de serviços, o trabalho temporário é amplamente utilizado nas empresas públicas. Conforme referido, o trabalho temporário traz vantagens tanto para a empresa de trabalho temporário, como para a empresa prestadora do serviço, e para o trabalhador temporário, mas em proporções diferentes, tudo devido à redução dos custos.

Para os trabalhadores, o trabalho temporário é aceito porque, dado o alto índice de desemprego, o trabalhador é obrigado a aceitar o trabalho temporário por necessidade e, além disso, a contratação do trabalho temporário reduz os direitos e benefícios pagos ao trabalhador quando vinculado por tempo indeterminado para uma determinada empresa.

A terceirização temporária, apesar de ter uma lei específica que a regulamenta, prejudica a vida daqueles trabalhadores que, devido ao desemprego, aceitam condições de vida instáveis.

Assim, este estudo conclui que cada gestor público deve promover um diagnóstico específico para a sua empresa e também para a sua situação, para que possa ter no seu quadro, profissionais temporários, se necessário, pois é sabido que mesmo nas empresas públicas, algumas áreas exigem conhecimentos muito específicos sobre um ou outro assunto, mas nada que o Estado não possa fornecer quando for realizado um concurso público para atender a essa demanda iminente.

Para trabalhos futuros, recomenda-se a feitura de um levantamento bibliométrico sobre a questão da terceirização em pesquisas stricto sensu feitas entre 2017 e 2021 . A ideia com esta pesquisa visa averiguar os impactos da Reforma Trabalhista de 2017 no âmbito das empresas, bem como de que forma as organizações estão gerenciando esta questão com vistas ao melhor aproveitamento de mão de obra, redução de custos e incremento em seus resultados. Outra situação possível a ser pesquisada seria a coleta de dados junto a trabalhadores temporários sobre suas perspectivas de vida e carreira na sociedade contemporânea.

\section{Referências}

Abílio, L.C. (2020). Uberização: informalização e o trabalhador just-in-time. Trab.educ.saúde, 19, 1 - 3.

Barreto, A.C.V. \& Honorato, C. F. (1998). Manual de sobrevivência na selva acadêmica. Rio de Janeiro: Objeto Direto.

Boaventura, E. M. (2004). Metodologia de pesquisa: monografia, dissertação, tese. São Paulo: Atlas.

Brasil (1943). Decreto-lei $n^{\circ}$ 5.452, de 1 de maio de 1943. Aprova a consolidação das leis do trabalho. Rio de Janeiro: Diário Oficial da União.

Brasil (1974). Lei $n^{\circ}$ 6.019, de 3 de janeiro de 1974. Dispõe sobre Trabalho Temporário em Empresas Urbanas e dá outras providências. Brasília: Diário Oficial da União.

Brasil (2017). Lei $n^{\circ} 13.429$, de 31 de março de 2017. Altera os dispositivos da Lei $n^{\circ} 6.019$, de 3 de janeiro de 1974 que dispõe sobre o trabalho temporário nas empresas urbanas e dá outras providências; e dispõe sobre as relações de trabalho na empresa de prestação de serviços a terceiros. Brasília: Senado Federal.

Bruno-Faria, M.F., Veiga, H.M. \& Macêdo, L.F. (2008). Criatividade nas organizações: análise da produção científica nacional em periódicos e livros de Administração e Psicologia. rPot, 8(1), 142 - 163.

Carvalho, V.S.R. (2020). Relevância dos critérios de adjudicação na escolha de fornecedores - o impacto na melhoria da qualidade de fornecimento. Dissertação de Mestrado, Universidade de Coimbra CO, Portugal. https://eg.uc.pt/handle/10316/92679

Druker, P. F. (1987). Inovação e espírito empreendedor. Editora Pioneira.

García-Aviles, J.A., Carvajal-Prieto, M., Lara-González, A. \& Arias-Robles, F. (2018). Developing an index of media innovation in a national market: the case of Spain. Journalism Studies, 19(1), $25-42$.

Gil, A.C. (2019). Como elaborar projetos de pesquisa. 7 th ed. São Paulo: Atlas.

Graban, M. (2013). Hospitais Lean. Porto Alegre: Bookman.

Gummesson, E. (1981). The Marketing of Professional Services. Chicago: American Marketing Association.

Inácio, D.B. (2021). Estratégias para o gerenciamento de crises na universidade. Dissertação de Mestrado, Universidade Federal de Santa Catarina, SC, Brasil. https://repositorio.ufsc.br/handle/123456789/229939 
Kotler, P. (1996). Administração de Marketing: análise, planejamento, implementação e controle. São Paulo: Atlas.

Maximiano, A.C.A. (2011). Teoria geral da Administração: da revolução urbana à revolução digital. São Paulo: Atlas.

Milan, G.S, Brentano, J. \& Toni, D. (2008). A qualidade percebida dos serviços prestados por uma agência de comunicação e a satisfação de clientes: um estudo exploratório. Revista Brasileira de Gestão de Negócios, 10(26), 17 - 26, 2008.

Mourão, L. \& Marins, J. (2009). Avaliação de treinamento e desenvolvimento nas organizações: resultados relativos ao nível de aprendizagem. Revista Psicologia: Organizações e Trabalho, 9(2), $72-85$.

Nascimento-e-Silva, D. (2017). Gestão de organizações de ciência e tecnologia: ferramentas e procedimentos básicos. Saarbrücken: Novas Edições Acadêmicas.

Pagnoncelli, D. (1993). Terceirização e parceria: estratégias para o sucesso empresarial. Rio de Janeiro: D. Pagnocelli.

Paraschivescu, A.O. \& Cotîrlet, P.C. (2015). Quality continuous improvement strategies kaizen strategy- comparative analysis. Economy Transdisciplinary Cognition, 18(1), $12-21$.

Pinto, R.S. (2004). Trabalho temporário: uma contribuição para a compreensão dos direitos do trabalhador diante do paradigma da flexibilização. Cadernos Estudos Jurídicos, 7(7), 1 - 194.

Portella, A.G. (2021). Aplicação do gerenciamento de projetos na execução de pesquisa de benchmarking. Revista Aquila, 24,41 - 55.

Puente-Palacios, K. \& Freitas, I.A. (2006). Clima organizacional: uma análise de sua definição e de seus componentes. Organizações \& Sociedade, 13(38), 45 -57 .

Queiroz, C. A. R. S. (1998). Manual de Outsourcing: onde podemos errar no desenvolvimento e implementação de projetos e quais os caminhos para o sucesso. São Paulo: STS.

Rabbi, B. \& Monteiro, F.N.C. (2018). Análise da viabilidade de implantação de uma franquia fast-food no município de Santo Antônio de Pádua utilizando ferramentas de gestão estratégica. Brazilian Journal of Development, 4(5), 2377 - 2393.

Redinha, M. R. G. A precariedade do emprego - uma interpelação ao direito do trabalho. In: Moreira, A. (coordenador). I Congresso Nacional de Direito do Trabalho, Livraria Almedina - Coimbra, 1995.

Silva, R.O. (2019). Proposta de autocapacitação para coordenadores de graduação. Dissertação de Mestrado, Instituto Federal de Educação, Ciências e Tecnologia do Amazonas, AM, Brasil. http://repositorio.ifam.edu.br/jspui/handle/4321/381

Silva, R.O. \& Nascimento-e-Silva, D. (2020). Impactos do novo Coronavírus nas organizações e as inovações no mundo do trabalho, saúde e educação. Colóquio Organizações, Desenvolvimento e Sustentabilidade, 11(1), 1 - 21.

Silva, M.O., Bantim, N. \& Costa, M.A.M. (2020). Precarização do trabalho no setor de eventos: um estudo inicial sobre os impactos para os trabalhadores e empresas. Revista de Turismo Contemporâneo, 9(1), 1 - 23.

Slack, N., Chambers, S. \& Johston, R. (2009). Administração da produção. 2th ed. São Paulo: Atlas.

Slee, T. (2017). Uberização: a nova onda do trabalho precarizado. São Paulo: Elefante.

Soeiro, J. (2013). Nada será como dantes? Uma semiose do trabalho temporário. Cescontexto-debates, 4, 102 - 111.

Wiegerinck. J. (1995). Trabalho Temporário na Prática. São Paulo: Makron Books.

Zanella, L.C.H. (2013). Metodologia de pesquisa. Florianópolis: Departamento de Ciências da Administração/UFSC. 